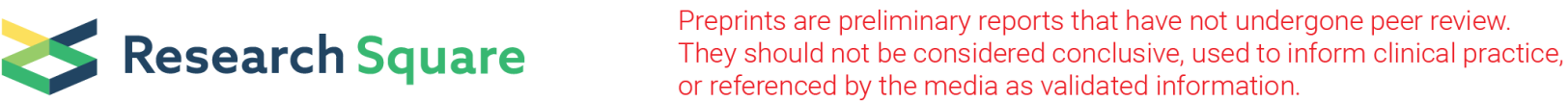

\section{Long-term survival of distal cholangiocarcinoma after pancreaticoduodenectomy combined with portal vein system resection and reconstruction}

\section{Shaocheng Lyu}

Beijing Chaoyang Hospital https://orcid.org/0000-0002-2757-7868

Lixin Li

Beijing Chaoyang Hospital

Xin Zhao

Beijing Chaoyang Hospital

Zhangyong Ren

Beijing Chaoyang Hospital

Di Cao

Beijing Chaoyang Hospital

Qiang He ( $\sim$ heqiang349@163.com )

https://orcid.org/0000-0002-5007-5225

\section{Research}

Keywords: Cholangiocarcinoma, Pancreatoduodenectomy, Portal vein system, Survival, Vascular invasion

Posted Date: June 9th, 2020

DOI: https://doi.org/10.21203/rs.3.rs-33592/v1

License: () (1) This work is licensed under a Creative Commons Attribution 4.0 International License.

Read Full License 


\section{Abstract \\ BACKGROUND:}

Pancreaticoduodenectomy is the only definitively curative therapy for the long-term survival of distal cholangiocarcinoma patients. And the 5-year survival rate of distal cholangiocarcinoma after pancreatoduodenectomy ranged from $22-47 \%$. Pancreatoduodenectomy combined with portal vein system resection and reconstruction for distal cholangiocarcinoma is rarely reported because it's not common. To our knowledge, only few reports have provided the detail outcome and long-term survival of distal cholangiocarcinoma after pancreaticoduodenectomy combined with portal vein system resection and reconstruction. Therefore, we developed a program to analysis the risk factors of prognosis for distal cholangiocarcinoma patients after pancreaticoduodenectomy, and to evaluate the vascular invasion type, operation procedure and long-term survival of patients with portal vein system invasion.

\section{METHODS:}

Retrospective reviewed for 123 distal cholangiocarcinoma patients after pancreatoduodenectomy between January 2011 and December 2019. Portal vein system invasion in 17 patients according to the pathology. Multivariable regression Cox models produced survival estimate to the distal cholangiocarcinoma patients. Then patients were grouped according to portal vein system invasion, and tumor-free and overall survival rates were investigated with the Kaplan-Meier analysis. Finally, the vascular invasion type and operation procedure were analyzed to the distal cholangiocarcinoma patients with portal vein system invasion.

\section{RESULTS:}

The 1-year, 3-year, 5-year overall survival rates of patients with distal cholangiocarcinoma after pancreatoduodenectomy were 75.2\%, 37.1\%, 31.5\%. Multifactor Cox regression showed tumour differentiation degree $(R R=1.440,95 \% C l: 1.009-2.055)$, portal vein system invasion $(R R=1.860$, $95 \% \mathrm{Cl}: 1.057-3.275)$ and lymph node metastasis $(R R=2.097,95 \% \mathrm{Cl}$ : $1.054-4.174)$ as independent risk factors for long-term survival. There were 17 patients underwent pancreatoduodenectomy combined with portal vein system resection and reconstruction. The patients with portal vein system invasion had larger tumor diameter, longer operation time, more blood transfusion rate and more lymph node metastasis rate than control group $(P<0.05)$. The 1-year, 2-year overall survival rates for patients without and with portal vein system invasion were $79.7 \%, 58.9 \%$ and $48.6 \%, 10.8 \%(p=0.000)$. The median overall survival time for patients without and with portal vein system invasion were 49.1 and 14.2 months, respectively.

\section{CONCLUSION:}


The portal vein system invasion is an important independent risk factors for long-term survival to the patients with distal cholangiocarcinoma, and the long-term survival is poor. Pancreatoduodenectomy combined with portal vein system resection and reconstruction did not increase the incidence of perioperative complication rate and mortality. At present, surgery maybe still the only effective method for distal cholangiocarcinoma patients with portal vein system invasion.

\section{Background}

Cholangiocarcinoma is a rare malignancy and accounts for $2 \%$ of all malignancies [1]. Distal cholangiocarcinoma refers to the extrahepatic bile duct where the tumor below the confluence of the cystic duct, accounting for $20-40 \%$ of all cholangiocarcinoma [2-3]. Surgical resection by pancreaticoduodenectomy remains the only definitively curative therapy for the long-term survival of distal cholangiocarcinoma patients [4]. And the 5-year survival rate of distal cholangiocarcinoma after pancreatoduodenectomy ranged from $22-47 \%[5-7]$.

Pancreatoduodenectomy combined with portal vein system resection and reconstruction for distal cholangiocarcinoma is rarely reported because it's not common. To our knowledge, only few reports have provided the detail outcome and long-term survival of distal cholangiocarcinoma after pancreaticoduodenectomy combined with portal vein system resection and reconstruction[8-9].

Therefore, we collectively reviewed 123 patients with distal cholangiocarcinoma after pancreaticoduodenectomy in our hospital, and there were 17 patients with portal vein system invasion. The aim of our study was to analyse the risk factors of prognosis for distal cholangiocarcinoma patients after pancreaticoduodenectomy, and to evaluate the vascular invasion type, operation procedure and long-term survival of patients with portal vein system invasion.

\section{Patients And Methods}

\section{Patients}

A retrospective analysis was made of 123 consecutive patients with distal cholangiocarcinoma who underwent pancreatoduodenectomy from January 2011 to December 2019 in the Department of Hepatobiliary Surgery of our hospital. All of the patients were diagnosed with adenocarcinoma according to the pathology. And the patients with no invasion of major celiac arteries (hepatic artery / celiac trunk / superior mesenteric artery) or distant metastasis. There were also 17 patients were diagnosed with portal vein system invasion according to the pathology.

The patients including 72 (58.5\%) males and 51 (41.5\%) females, and the age of the patients ranged from 29 to 84 years (mean, $64.9 \pm 9.2$ years). Forty-two (34.1\%) patients underwent percutaneous transhepatic cholangial drainage (PTCD) before operation, and $16(13.0 \%)$ patients underwent endoscopic retrograde cholangiopancreatography (ERCP) before operation. The radiological information was acquired from the latest CT or MRI examination before operation. 
This study was approved by the Ethics Committee of Beijing Chaoyang Hospital (acceptance number 2020-D-141). All procedures in this study involving human participants were performed in accordance with the ethical standards of the institutional research committee and the 1964 Helsinki Declaration.

\section{Treatment and Follow-up}

All of the patients underwent pancreatoduodenectomy. And regional lymph node dissection was performed routinely during the operation, including nodes along the common hepatic artery, nodes in the hepatoduodenal ligament, and anterior or posterior pancreatoduodenal nodes. And the portal vein system resection and reconstruction was performed to the patients with vascular invasion.

Patients were followed up by outpatient and telephone. Blood routine and blood biochemistry examination every one month, carbohydrate antigen 19 - 9 (CA19-9) and CT scan every 3 months for 2 years. Then CA19-9 and CT scan every 6 months above 2 years.

\section{Statistical analysis}

Catalogued data included general conditions (gender, age, diabetes history, smoking history, biliary drainage history, leukocyte, neutrophil ratio, alanine aminotransferase (ALT), aspartate aminotransferase (AST ), total bilirubin (TB), direct bilirubin (DB), glutamyltranspeptidase (GGT), albumin (ALB), CEA, CA199), intraoperative conditions (operation time, bleeding volume, blood transfusion), pathological conditions (maximum tumor diameter, tumour differentiation degree, perineural invasion, portal vein system invasion, lymph node metastasis, $\mathrm{T}$ stage, $\mathrm{R} 0$ resection) and follow-up conditions (postoperative complication, postoperative chemotherapy, tumour recurrence and long-term survival) .

Endpoints for the current analysis was patient death or tumour recurrence. The normal distribution data was represented by mean $\pm S D$, and comparisons were analyzed with the Student t-test according to data distribution. The non normal distribution data was represented by M (P25, P75)

, and comparisons were analyzed with the Mann-Whitney rank-sum test. Categorical variables were presented as number and percentage and were analyzed by Chi-square test or Fisher exact test, as appropriate.

Overall and tumour-free survival rates were calculated using the Kaplan-Meier method. Log-rank test was used to perform the univariate analysis, and Cox proportional hazard regression models were used for multivariate analysis. Those variables, which were found to be significant in univariate analysis, were further enrolled in the multivariate analysis.

A p value $<0.05$ was considered statistically significant. The statistical measurements were performed using the SPSS 19.0 (IBM, Chicago, Illinois, USA) software program.

\section{Results}

\section{Perioperative outcomes}


All of the 123 patients successfully completed the operation. The amount of bleeding was $500(400,600)$ $\mathrm{ml}, 43$ patients received blood transfusion, and the operation time ranged from 6 to 15 hours (mean, $9.8 \pm$ 1.9 hours). R0 resection in 117 patients with the R0 rate of $95.1 \%$. The tumor size ranged from 0.5 to $6.5 \mathrm{~cm}$ (mean, $2.2 \pm 1.0 \mathrm{~cm}$ ). Lymph node metastases in 51 patients with the rate of $41.5 \%$. Portal vein system invasion in 17 patients according to the pathology.

In our group, 6 patients died during the perioperative period, and the perioperative mortality was $4.9 \%$. The causes of deaths included haemorrhage 3 cases, myocardial infarction 1 case, pulmonary embolism 1 case and cerebral hemorrhage 1 case. There were 34 patients with postoperative complications, and the incidence rate was $27.6 \%$. Among them, biochemical fistula in $14(11.4 \%)$ cases, grade B pancreatic fistula in 7 (5.7\%) cases, grade C pancreatic fistula in 5 (4.1\%) cases, haemorrhage in 9 (7.3\%) cases.

\section{Prognostic outcomes}

The final follow-up date is April 2020, and the median follow-up length is 41.0 months. Two patients missed follow-up. Finally, 115 patients were studied of long-term survival. The 1-year, 3-year, 5-year tumour-free and overall survival rates of all patients were $67.0 \%, 36.0 \%, 27.1 \%$ and $75.2 \%, 37.1 \%, 31.5 \%$ (Fig. 1A and 1B). The median tumour-free and overall survival time were 38.2 and 44.7 months, respectively.

\section{Risk factors for long-term survival of distal cholangiocarcinoma after pancreatoduodenectomy}

In the 115 patients, univariate analysis identified neutrophil ratio, CA19-9, tumour differentiation degree, perineural invasion, portal vein system invasion and lymph node metastasis as the risk factors for longterm survival of distal cholangiocarcinoma patients after pancreatoduodenectomy (Table 1). And multifactor Cox regression showed tumour differentiation degree $(R R=1.440,95 \% C l: 1.009-2.055)$, portal vein system invasion $(R R=1.860,95 \% C l$ : $1.057-3.275)$ and lymph node metastasis $(R R=2.097$, 95\% Cl. 1.054-4.174) as independent risk factors for long-term survival (Table 2).

Table 1. Risk factors for long-term survival of distal cholangiocarcinoma patients after pancreatoduodenectomy by univariate analysis 


\begin{tabular}{|c|c|c|c|c|c|}
\hline$\overline{\text { les }}$ & $\begin{array}{l}\text { No. } \\
\text { patients }\end{array}$ & $\begin{array}{l}\text { 1-year survival } \\
(\%)\end{array}$ & $\begin{array}{l}\text { 3-year survival } \\
(\%)\end{array}$ & $\begin{array}{l}\text { Median survival } \\
\text { (month) }\end{array}$ & $\begin{array}{l}\mathrm{P} \\
\text { value }\end{array}$ \\
\hline \multicolumn{6}{|c|}{ r } \\
\hline & 70 & 75.6 & 42.6 & 41.4 & \multirow[t]{2}{*}{0.905} \\
\hline ale & 45 & 74.8 & 31.2 & 44.7 & \\
\hline \multicolumn{6}{|c|}{ әar) } \\
\hline & 60 & 77.8 & 37.3 & 47.4 & \multirow[t]{2}{*}{0.409} \\
\hline & 55 & 72.3 & 36.7 & 37.7 & \\
\hline \multicolumn{6}{|l|}{ es } \\
\hline & 31 & 76.1 & 37.4 & 45.3 & \multirow{2}{*}{0.753} \\
\hline & 84 & 74.8 & 37.0 & 41.5 & \\
\hline & 37 & 79.8 & 31.2 & 32.0 & 0.441 \\
\hline & 78 & 73.2 & 38.8 & 48.4 & \\
\hline \multicolumn{6}{|c|}{ drainage } \\
\hline & 51 & 77.4 & 32.4 & 43.3 & \multirow[t]{2}{*}{0.860} \\
\hline & 64 & 73.4 & 41.4 & 43.1 & \\
\hline \multicolumn{6}{|c|}{ :yte $\left(* 10^{9}\right)$} \\
\hline & 104 & 74.6 & 34.7 & 42.5 & \multirow[t]{2}{*}{0.179} \\
\hline & 11 & 81.8 & 68.2 & 60.2 & \\
\hline \multicolumn{6}{|c|}{ sphil ratio (\%) } \\
\hline & 90 & 82.3 & 39.5 & 47.7 & \multirow[t]{2}{*}{0.038} \\
\hline & 25 & 49.6 & 27.9 & 32.0 & \\
\hline \multicolumn{6}{|l|}{ /L) } \\
\hline & 61 & 69.2 & 40.8 & 40.2 & \multirow[t]{2}{*}{0.122} \\
\hline & 54 & 82.4 & 46.1 & 35.8 & \\
\hline \multicolumn{6}{|l|}{ r/L) } \\
\hline & 30 & 82.5 & 34.5 & 43.1 & \multirow[t]{2}{*}{0.896} \\
\hline & 85 & 72.5 & 37.9 & 42.4 & \\
\hline \multicolumn{6}{|c|}{ I/L) } \\
\hline & 29 & 76.7 & 43.7 & 44.5 & \multirow[t]{2}{*}{0.630} \\
\hline & 86 & 74.7 & 35.9 & 43.0 & \\
\hline \multicolumn{6}{|c|}{$10 l / L)$} \\
\hline & 17 & 94.1 & 62.7 & 57.2 & \multirow[t]{2}{*}{0.062} \\
\hline & 98 & 71.6 & 33.3 & 41.2 & \\
\hline \multicolumn{6}{|c|}{ nol/L) } \\
\hline & 11 & 90.9 & 63.6 & 34.3 & \multirow[t]{2}{*}{0.196} \\
\hline & 104 & 73.3 & 35.0 & 43.0 & \\
\hline \multicolumn{6}{|c|}{$J / L)$} \\
\hline & 9 & 76.2 & 40.6 & 26.6 & \multirow[t]{2}{*}{0.896} \\
\hline & 106 & 75.2 & 37.3 & 44.7 & \\
\hline $\mathrm{lg} / \mathrm{m}$ & & & & & \\
\hline & 101 & 75.9 & 41.3 & 47.3 & 0.073 \\
\hline & 14 & 70.7 & 10.5 & 24.6 & \\
\hline$\exists(U$ & & & & & \\
\hline & 40 & 86.7 & 52.3 & 50.9 & 0.031 \\
\hline & & & Page $6 / 18$ & & \\
\hline
\end{tabular}


75

68.9

ion time (h)

49

66

76.0

74.7

Ig volume (ml)

53

72.3

77.8

ransfusion

39

69.5

78.0

ntiation

29

51

ərate

35

diameter $(\mathrm{cm})$

44

71

85.2

77.3

63.5

88.5

66.0

ural invasion

104

73.6

90.9

11

vein system

$\mathrm{n}$

16

99

48.6

79.7

63.5

node metastasis 68

\begin{tabular}{ll}
$47 \quad 63.5$ \\
\hline
\end{tabular}

83.0

110

74.9

ection

5

2

11

102

28

erative

87

cation

37
78

erative

therapy
29.1

38.0

43.9

43.9

0.372

33.2

41.2

38.0

45.3

43.4

0.883

36.9

30.5

35.1

0.078

39.5

43.4

50.8

52.6

0.016

34.8

43.5

31.3

28.6

38.9

46.4

0.162

35.8

41.3

32.4

38.4

0.015

90.9

93.0

14.2

0.000

42.4

49.1

19.0

27.5

0.000

50.7

55.5

38.2

45.4

0.464

20.0

23.4

100

0.281

47.1

48.7

34.8

42.4

26.0

31.4

0.250

40.1

47.9

38.4

36.3

40.2

0.784

41.0 
Table 2

Risk factors for long-term survival of distal cholangiocarcinoma patients after pancreatoduodenectomy by multivariate Cox regression

\begin{tabular}{|llll|}
\hline Variables & $R R$ & $95 \% ~ C l$ & P value \\
\hline Neutrophil ratio & 1.555 & $0.876-2.760$ & 0.131 \\
\hline CA19-9 & 1.364 & $0.766-2.430$ & 0.292 \\
\hline Differentiation & 1.440 & $1.009-2.055$ & 0.045 \\
\hline Perineural invasion & 3.972 & $0.530-29.771$ & 0.180 \\
\hline Portal vein system invasion & 1.860 & $1.057-3.275$ & 0.032 \\
\hline Lymph node metastasis & 2.097 & $1.054-4.174$ & 0.035 \\
\hline
\end{tabular}

\section{Clinical features of patients with portal vein system invasion}

All of the 123 patients were divided into portal vein system invasion group and control group according to the presence or absence portal vein system invasion. The clinical features comparison between the two groups were shown in Table 3. The patients with portal vein system invasion had larger tumor diameter, longer operation time, more blood transfusion rate and more lymph node metastasis rate than control group $(P<0.05)$. However, pancreatoduodenectomy combined with vascular resection and reconstruction did not increase the incidence of perioperative complication rate and mortality. 
Table 3

Clinical features comparison between the portal vein system invasion group and control group

\begin{tabular}{|c|c|c|c|}
\hline Variables & $\begin{array}{l}\text { portal vein system invasion group ( } \mathrm{n} \\
=17 \text { ) }\end{array}$ & $\begin{array}{l}\text { control group } \\
(n=106)\end{array}$ & $\begin{array}{l}P \\
\text { value }\end{array}$ \\
\hline Age(year) & $62.4 \pm 9.8$ & $65.7 \pm 8.9$ & 0.164 \\
\hline Leukocyte $\left({ }^{*} 10^{9}\right)$ & $6.5 \pm 1.7$ & $6.8 \pm 2.3$ & 0.651 \\
\hline Neutrophil ratio (\%) & $69.1 \pm 9.1$ & $66.3 \pm 10.5$ & 0.300 \\
\hline $\operatorname{ALB}(\mathrm{g} / \mathrm{L})$ & $34.1 \pm 4.4$ & $34.4 \pm 6.2$ & 0.848 \\
\hline $\operatorname{ALT}(\mathrm{U} / \mathrm{L})$ & $111.0(41.0,159.0)$ & $65.5(34.0,151.3)$ & 0.473 \\
\hline AST (U/L) & $67.0(32.0,120.0)$ & $58.0(37.8,103.0)$ & 0.815 \\
\hline TB $(\mu \mathrm{mol} / \mathrm{L})$ & $117.1(30.3,224.9)$ & $\begin{array}{l}\text { 105.9(33.6, } \\
216.8)\end{array}$ & 0.823 \\
\hline $\mathrm{DB}(\mu \mathrm{mol} / \mathrm{L})$ & $109.0(25.5,202.2)$ & $81.1(21.9,167.2)$ & 0.731 \\
\hline GGT (U/L) & $396.0(151.0,706.0)$ & $\begin{array}{l}370.0(129.0 \\
772.5)\end{array}$ & 0.988 \\
\hline CEA (ng/ml) & $2.5(1.9,3.2)$ & $2.2(1.3,3.4)$ & 0.162 \\
\hline CA19-9 (U/ml) & $80.2(37.4,410.9)$ & $53.1(25.5,170.8)$ & 0.270 \\
\hline Tumor diameter $(\mathrm{cm})$ & $3.0 \pm 1.4$ & $2.1 \pm 0.9$ & 0.001 \\
\hline Bleeding volume $(\mathrm{ml})$ & $600.0(400.0,1500.0)$ & $\begin{array}{l}500.0(400.0 \\
600.0)\end{array}$ & 0.288 \\
\hline Operation time (h) & $11.8 \pm 2.2$ & $9.5 \pm 1.6$ & 0.000 \\
\hline ICU stay (day) & $4.0(2.0,6.0)$ & $2.0(1.0,4.0)$ & 0.060 \\
\hline $\begin{array}{l}\text { Postoperative hospital stay } \\
\text { (day) }\end{array}$ & $21.0(17.0,26.0)$ & $21.0(16.0,26.0)$ & 0.953 \\
\hline \multicolumn{4}{|l|}{ Gender (\%) } \\
\hline Male & 12(70.6) & $60(56.6)$ & 0.277 \\
\hline Female & $5(29.4)$ & $46(43.4)$ & \\
\hline \multicolumn{4}{|l|}{ Diabetes history (\%) } \\
\hline Yes & $4(23.5)$ & $30(28.3)$ & 0.907 \\
\hline No & 13(76.5) & 76(71.7) & \\
\hline \multicolumn{4}{|l|}{ Smoking history (\%) } \\
\hline Yes & $5(29.4)$ & $33(31.1)$ & 0.887 \\
\hline
\end{tabular}




\begin{tabular}{|c|c|c|c|}
\hline Variables & $\begin{array}{l}\text { portal vein system invasion group ( } \mathrm{n} \\
=17 \text { ) }\end{array}$ & $\begin{array}{l}\text { control group } \\
(n=106)\end{array}$ & $\begin{array}{l}P \\
\text { value }\end{array}$ \\
\hline No & 12(70.6) & $73(68.9)$ & \\
\hline \multicolumn{4}{|c|}{ Biliary drainage history (\%) } \\
\hline Yes & $9(52.9)$ & $49(46.2)$ & 0.607 \\
\hline No & $8(47.1)$ & $57(53.8)$ & \\
\hline \multicolumn{4}{|c|}{ Blood transfusion (\%) } \\
\hline Yes & $10(58.8)$ & $33(31.1)$ & 0.026 \\
\hline No & $7(41.2)$ & $73(68.9)$ & \\
\hline \multicolumn{4}{|c|}{ Differentiation (\%) } \\
\hline Poor & $7(41.2)$ & $29(27.4)$ & 0.497 \\
\hline Moderate & $7(41.2)$ & $51(48.1)$ & \\
\hline Well & $3(17.6)$ & $26(24.5)$ & \\
\hline \multicolumn{4}{|c|}{ Perineural invasion (\%) } \\
\hline Yes & 17(100) & $91(85.8)$ & 0.209 \\
\hline No & $0(0)$ & $15(14.2)$ & \\
\hline \multicolumn{4}{|c|}{ Lymph node metastasis (\%) } \\
\hline Yes & 13(76.5) & $38(35.8)$ & 0.002 \\
\hline No & $4(23.5)$ & $68(64.2)$ & \\
\hline \multicolumn{4}{|c|}{ Resection (\%) } \\
\hline RO & 16(94.1) & $101(95.3)$ & 1.000 \\
\hline R1 & $1(5.9)$ & $5(4.7)$ & \\
\hline \multicolumn{4}{|c|}{ T stage (\%) } \\
\hline T1 & $0(0)$ & $2(1.9)$ & 0.254 \\
\hline $\mathrm{T} 2$ & $0(0)$ & 13(12.3) & \\
\hline T3 & 17(100) & $91(85.8)$ & \\
\hline \multicolumn{4}{|c|}{$\begin{array}{l}\text { Postoperative complication } \\
\text { (\%) }\end{array}$} \\
\hline Yes & $3(17.6)$ & $31(29.2)$ & 0.484 \\
\hline
\end{tabular}




\begin{tabular}{|llll|}
\hline Variables & $\begin{array}{l}\text { portal vein system invasion group }(\mathbf{n} \\
=17)\end{array}$ & $\begin{array}{l}\text { control group } \\
(\mathbf{n}=106)\end{array}$ & $\begin{array}{l}\mathbf{P} \\
\text { value }\end{array}$ \\
\hline No & $14(82.4)$ & $75(70.8)$ & \\
\hline Perioperative death (\%) & & & \\
\hline Yes & $1(5.9)$ & $5(4.7)$ & \\
\hline No & $16(94.1)$ & $101(95.3)$ & \\
\hline
\end{tabular}

\section{Method of portal vein system resection and reconstruction}

The location of portal vein system invasion by distal cholangiocarcinoma was showed in Fig. 3, and the location mainly contains portal vein $(P V, n=6)$, junction of portal vein and superior mesenteric vein (SMV, $n=7)$ and superior mesenteric vein $(n=4)$. The method of portal vein system resection and reconstruction was showed in Table 4 . Wedge resection followed by primary closure was performed in 4 patients. Segmental resection was performed in 6 patients with PV or SMV invasion, and 4 patients were reconstructed by end-to-end anastomosis, 2 patients were reconstructed by the venous allograft with shape of "I". Segmental resection was performed in 7 patients with junction of PV and SMV invasion, and the venous allograft with shape of " $Y$ " were used to reconstruction.

Table 4

Resection and reconstruction method of portal vein system invasion

\begin{tabular}{|llll|}
\hline Method & $\begin{array}{l}\text { PV invasion } \\
(\mathbf{n}=\mathbf{6})\end{array}$ & $\begin{array}{l}\text { SMV invasion } \\
(\mathbf{n}=\mathbf{4})\end{array}$ & junction of PV and SMV invasion $(\mathrm{n}=\mathbf{7})$ \\
\hline Resection & & 3 & 0 \\
\hline Wedge & 1 & 1 & 7 \\
\hline Segmental & 5 & & \\
\hline Reconstruction & & 3 & 0 \\
\hline Primary closure & 1 & 1 & 0 \\
\hline End-to-end & 3 & 0 & 7 \\
\hline Venous allograft & 2 & 0 & \\
\hline
\end{tabular}

\section{Prognostic outcomes of patients with portal vein system invasion}

The final follow-up date is April 2020, one patient was dead during the perioperative period in the 17 distal cholangiocarcinoma patients with portal vein system invasion. Finally, 16 patients were studied of long-term survival. The 1-year, 2-year, 3-year tumour-free survival rates for patients without and with portal vein system invasion were $73.3 \%, 53.2 \%, 40.5 \%$ and $31.3 \%,-,-(p=0.000$, Fig. $2 A)$. And the 1-year, 2-year, 
3-year overall survival rates were $79.7 \%, 58.9 \%, 42.4 \%$ and $48.6 \%, 10.8 \%,-(p=0.000$, Fig. 2B). The median tumour-free, overall survival time for patients without and with portal vein system invasion were 42.0, 49.1 and $10.2,14.2$ months, respectively.

\section{Discussion}

At present, the optimum treatment of distal cholangiocarcinoma is still based on surgery, and pancreatoduodenectomy is the standard operation [10-11]. Andrianello et al. [12] reviewed the data of 1490 cases of distal cholangiocarcinoma after pancreatoduodenectomy in the United States. The overall median survival time is 31 months, and the 1-year and 3-year survival rates are $89 \%$ and $40 \%$, respectively. Our research showed the 1 -year and 3 -year survival rates were $75.2 \%$ and $37.1 \%$.

Because of the lack of effective adjuvant therapy, it is very important to determine the risk factors of survival before operation for the long-term prognosis of patients. Our study showed tumour differentiation degree, portal vein system invasion and lymph node metastasis as independent risk factors for long-term survival. It's known to all that tumour differentiation degree and lymph node metastasis are the important risk factors for the long-term survival [13-17]. But previous studies have not paid enough attention because the portal vein system invasion is not common in distal cholangiocarcinoma. So the portal vein system invasion is not included as the standard of T stage in the 8th AJCC TNM classification system. The portal vein system invasion rate was reported to range from $6.2-9.4 \%$ in patients with distal cholangiocarcinoma[8-9, 18]. Maeta et al. [8] reviewed 453 patients with distal cholangiocarcinoma who underwent pancreatoduodenectomy in 31 medical center, the portal vein system invasion rate was $6.8 \%(31 / 453)$ among them. The portal vein system invasion rate was $13.8 \%$ in our study, and it is similar to the previous reports. We thought the reason for the low portal vein system invasion rate is that the distal bile duct is surrounded by the pancreas anatomically.

Therefore, only a few studies have reported the relationship between the portal vein system invasion and the long-term survival. Miura et al. [9] reviewed 129 patients with distal cholangiocarcinoma who underwent pancreatoduodenectomy. Eight patients were diagnosed with the portal vein system invasion, and the 3-year survival rate was $17 \%$ which was lower than the patients without the portal vein system invasion $(50 \%, P<0.01)$. And multifactor Cox regression showed the portal vein system invasion was the only independent risk factor for long-term prognosis. Bahra et al. [18] reported the median survival time was 11.2 months in the 9 patients of distal cholangiocarcinoma with the portal vein system invasion. Our study also showed the poor survival of the portal vein system invasion patients with the median survival time was 14.2 months. And we also found the portal vein system invasion patients had larger tumor diameter and more lymph node metastasis rate than the patients without the portal vein system invasion. So we thought the reason of portal vein system invasion is related to the aggressive and behaviour of the tumor itself.

Although the long-term survival of distal cholangiocarcinoma patients with portal vein system invasion is poor, surgery may still be the only effective method because the lack of evidence-based adjuvant 
treatment options [19]. The key of pancreatoduodenectomy combined with portal vein system resection is how to reconstruct the portal vein system safely [20]. Our experience is the reasonable reconstruction method should be selected according to the range, length and anastomotic tension of the resected vessels. Primary closure is suitable for wedge resection. End-to-end anastomosis is a good choice for segmental resection, but it's not suitable for a wide range segmental resection with high anastomotic tension. So we used the cold storage venous allograft to reconstruct the portal vein system for the patients with a wide range vascular segmental resection. And it's still another problem to the patients with junction of PV and SMV invasion. We used the cold storage venous allograft with shape of " $Y$ " to reconstruct the portal vein system, in order to recover the blood flow of spleen vein. Our study showed pancreatoduodenectomy combined with portal vein system resection and reconstruction had longer operation time and more blood transfusion rate than the control group $(P<0.05)$. However, it did not increase the incidence of perioperative complication rate and mortality. And we also found no complication relate to the venous allograft.

The limitation of our study is a retrospective analysis. And we don't have enough evidence that surgery is the best treatment for the distal cholangiocarcinoma patients with portal vein system invasion because there are too few chemotherapy patients. Furthermore, we also don't have a control group of non-surgical patients with portal vein system invasion. Nevertheless, our study is the largest single center sample of distal cholangiocarcinoma patients who underwent pancreatoduodenectomy combined with portal vein system resection and reconstruction.

\section{Conclusions}

In conclusion, the portal vein system invasion is an important independent risk factors for long-term survival to the patients with distal cholangiocarcinoma, and the long-term survival is poor. There is no high-level evidence-based medical basis for the best treatment because there are few clinical reports of distal cholangiocarcinoma patients with portal system invasion [21]. And it is also not clear whether it can improve the long-term survival by adjuvant therapy. In the present study, surgery maybe still the only effective method for these patients [22].

\section{Declarations}

\section{Ethics approval and consent to participate:}

Our research was approved by the Ethics Committee of Beijing Chaoyang Hospital with the approval number of 2020-D-141.

\section{Consent for publication:}

Written informed consent for publication was obtained from all participants. 
Availability of data and materials:

We do not wish to share our data because it is personal. We can provide it if the editor needs it, but we refuse to share the data publicly.

\section{Competing interests:}

No benefits in any form have been received or will be received from a commercial party related directly or indirectly to the subject of this article.

\section{Funding:}

Not applicable.

\section{Authors' contributions:}

HQ proposed the study. LSC performed the research and wrote the first draft. All authors contributed to the design and interpretation of the study and to further drafts. HQ is the guarantor.

\section{Acknowledgements:}

We will thank the patients for their great help in this report. This paper is supported by Dr. HQ.

\section{References}

1. Khan AS, Dageforde LA. Cholangiocarcinoma. Surg Clin North Am. 2019;99(2):315-35.

2. Al Mahjoub A, Bouvier V, Menahem B, Bazille C, Fohlen A, Alves A, Mulliri A, Launoy G, Lubrano J. Epidemiology of intrahepatic, perihilar, and distal cholangiocarcinoma in the French population. Eur J Gastroenterol Hepatol. 2019;31(6):678-84.

3. Forner A, Vidili G, Rengo M, Bujanda L, Ponz-Sarvisé M, Lamarca A. Clinical presentation, diagnosis and staging of cholangiocarcinoma. Liver Int. 2019;39(Suppl 1):98-107.

4. Strijker M, Belkouz A. van der Geest LG, van Gulik TM, van Hooft JE, de Meijer VE, Haj Mohammad N, de Reuver PR, Verheij J. de Vos-Geelen J, Wilmink JW, Groot Koerkamp B, Klümpen HJ, Besselink MG; Dutch Pancreatic Cancer Group. Treatment and survival of resected and unresected distal cholangiocarcinoma: a nationwide study. Acta Oncol 2019;58(7):1048-55.

5. Beetz O, Klein M, Schrem H, Gwiasda J, Vondran FWR, Oldhafer F, Cammann S, Klempnauer J, Oldhafer KJ, Kleine M. Relevant prognostic factors influencing outcome of patients after surgical resection of distal cholangiocarcinoma. BMC Surg. 2018;18(1):56. 
6. Wellner UF, Shen Y, Keck T, Jin W, Xu Z. The survival outcome and prognostic factors for distal cholangiocarcinoma following surgical resection: a meta-analysis for the 5-year surviva. Surg Today. 2017;47(3):271-9.

7. Cloyd JM, Prakash L, Vauthey JN, Aloia TA, Chun YS, Tzeng CW, Kim MP, Lee JE. Katz MHG. The role of preoperative therapy prior to pancreatoduodenectomy for distal cholangiocarcinoma. Am J Surg. 2019;218(1):145-50.

8. Maeta T, Ebata T, Hayashi E, Kawahara T, Mizuno S, Matsumoto N, Ohta S, Nagino M. Nagoya Surgical Oncology Group. Pancreatoduodenectomy with portal vein resection for distal cholangiocarcinoma. Br J Surg. 2017;104(11):1549-57.

9. Miura F, Sano K, Amano H, Toyota N, Wada K, Yoshida M, Hayano K, Matsubara H, Takada T. Evaluation of portal vein invasion of distal cholangiocarcinoma as borderline resectability. $\mathrm{J}$ Hepatobiliary Pancreat Sci. 2015;22(4):294-300.

10. Lee RM, Maithel SK. Approaches and outcomes to distal cholangiocarcinoma. Surg Oncol Clin N Am. 2019;28(4):631-43.

11. Lad N, Kooby DA. Distal cholangiocarcinoma. Surg Oncol Clin N Am. 2014;23(2):265-87.

12. Andrianello S, Paiella S, Allegrini V, Ramera M, Pulvirenti A, Malleo G, Salvia R, Bassi C.

Pancreaticoduodenectomy for distal cholangiocarcinoma: surgical results, prognostic factors, and long-term follow-up. Langenbecks Arch Surg 2015;400(5):623-8.

13. Kim HJ, Kim CY, Hur YH, Koh YS, Kim JC, Kim HJ, Cho CK. Prognostic factors for survival after curative resection of distal cholangiocarcinoma: perineural invasion and lymphovascular invasion. Surg Today 2014;44(10):1879-86.

14. Komaya K, Ebata T, Shirai K, Ohira S, Morofuji N, Akutagawa A, Yamaguchi R, Nagino M. Nagoya Surgical Oncology Group. Recurrence after resection with curative intent for distal cholangiocarcinoma. Br J Surg. 2017;104(4):426-33.

15. Zhou Y, Liu S, Wu L, Wan T. Survival after surgical resection of distal cholangiocarcinoma: $A$ systematic review and meta-analysis of prognostic factors. Asian J Surg. 2017;40(2):129-38.

16. Byrling J, Andersson R, Sasor A, Lindell G, Ansari D, Nilsson J, Andersson B. Outcome and evaluation of prognostic factors after pancreaticoduodenectomy for distal cholangiocarcinoma. Ann Gastroenterol. 2017;30(5):571-7.

17. Kiriyama M, Ebata T, Aoba T, Kaneoka Y, Arai T, Shimizu Y, Nagino M, Nagoya Surgical Oncology Group. Prognostic impact of lymph node metastasis in distal cholangiocarcinoma. Br J Surg. 2015;102(4):399-406.

18. Bahra M, Jacob D, Langrehr JM, Neumann UP, Neuhaus P. Carcinoma of the distal and middle bile duct: surgical results, prognostic factors, and long-term follow-up. J Hepatobiliary Pancreat Surg. 2008;15(5):501-7.

19. Bergeat D, Turrini O, Courtin-Tanguy L, Truant S, Darnis B, Delpero JR, Mabrut JY, Regenet N, Sulpice L. Impact of adjuvant chemotherapy after pancreaticoduodenectomy for distal cholangiocarcinoma: 
a propensity score analysis from a French multicentric cohort. Langenbecks Arch Surg. 2018;403(6):701-9.

20. Zhu J, Li X, Kou J, Ma J, Li L, Fan H, Lang R, He Q. Proposed Chaoyang vascular classification for superior mesenteric-portal vein invasion, resection, and reconstruction in patients with pancreatic head cancer during pancreaticoduodenectomy - A retrospective cohort study. Int J Surg. 2018;53:292-7.

21. Groeschl RT, Nagorney DM. Portal vein reconstruction during surgery for cholangiocarcinoma. Curr Opin Gastroenterol. 2016;32(3):216-24.

22. Nagino M. Fifty-year history of biliary surgery. Ann Gastroenterol Surg. 2019;3(6):598-605.

\section{Figures}
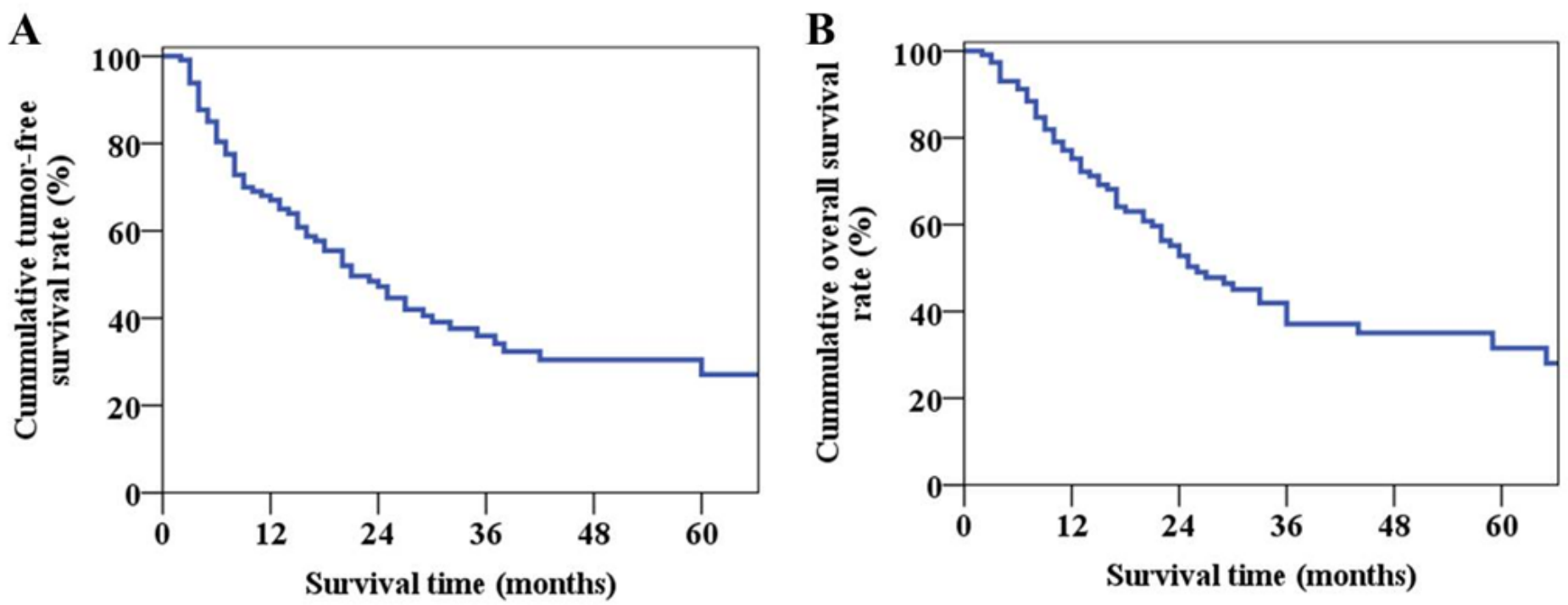

Figure 1

The tumour-free (A) and overall (B) survival curves for all patients. 

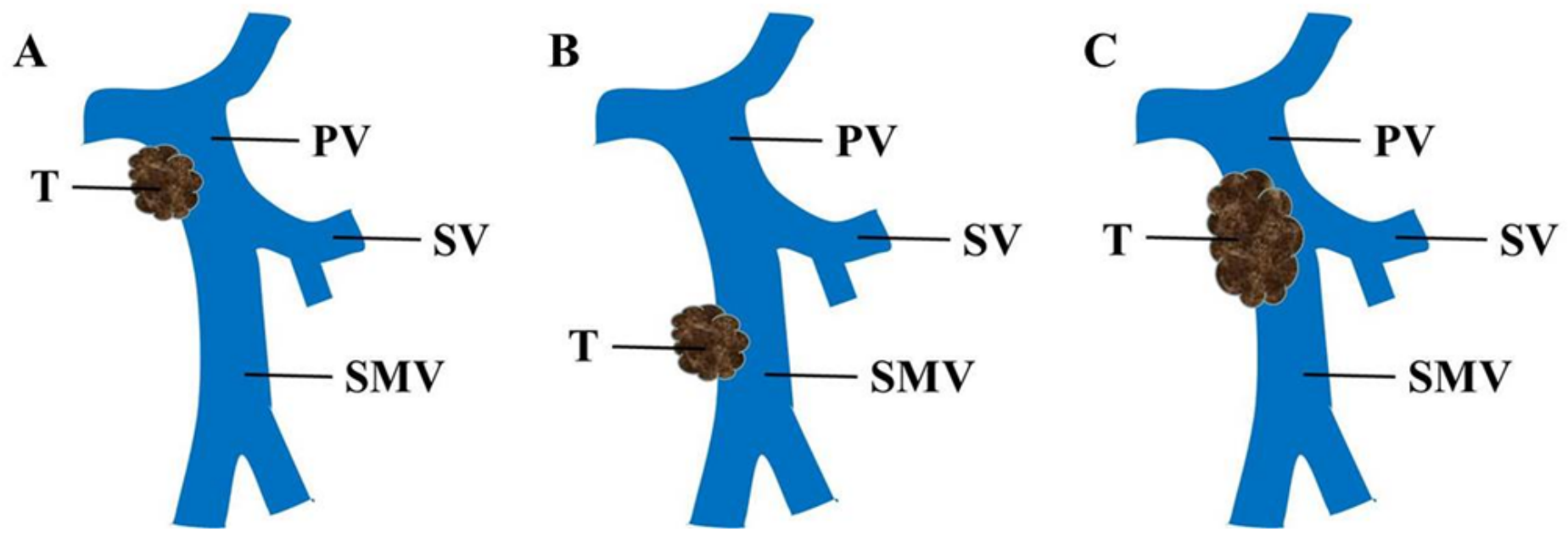

Figure 2

The location of portal vein system invasion by distal cholangiocarcinoma: $A$ (portal vein), B(junction of portal vein and superior mesenteric vein) and C(superior mesenteric vein). T: tumor; PV: portal vein; SMV: superior mesenteric vein; SV: splenic vein.
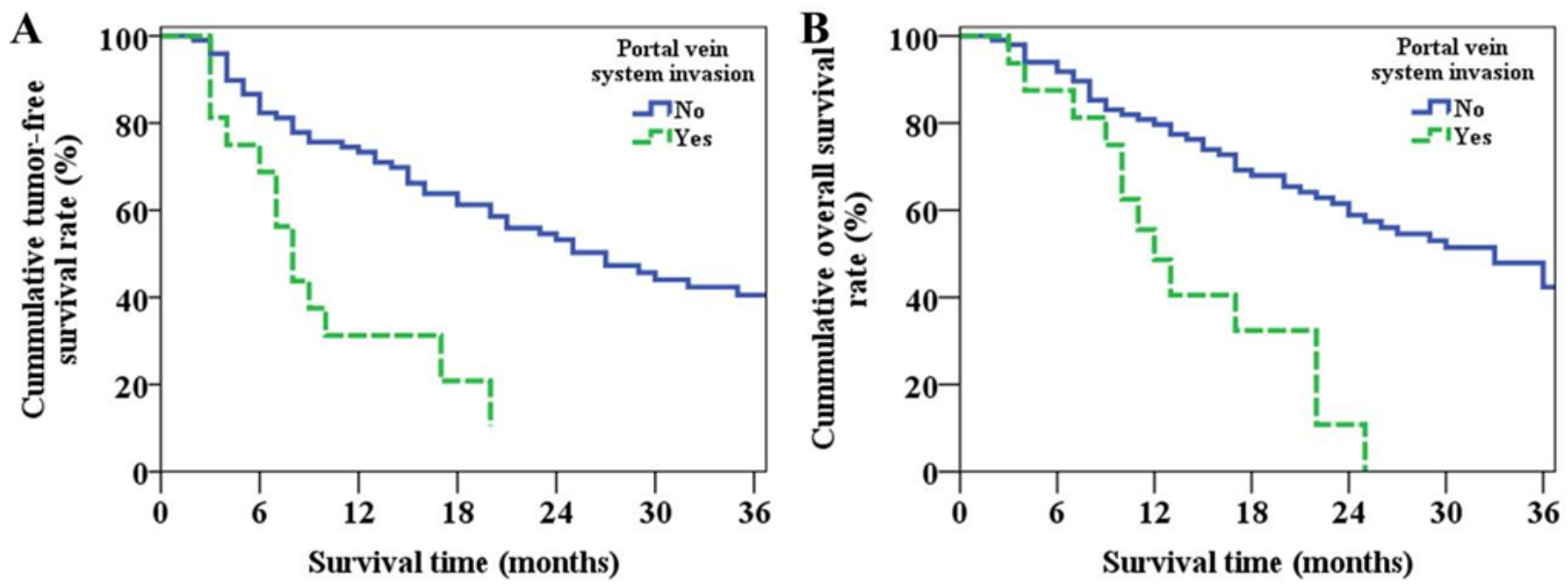

Figure 3

The tumour-free (A) and overall (B) survival curves for patients with or without portal vein system invasion.

\section{Supplementary Files}

This is a list of supplementary files associated with this preprint. Click to download. 
- ethicscommitteeinformation.pdf 